\title{
Pharmacist-led counselling intervention to improve antiretroviral drug adherence in Pakistan: a randomized controlled trial
}

\author{
Zeenat Fatima Chatha', Usman Rashid ${ }^{2}$, Sharon Olsen², Fakhar ud Din ${ }^{1 *}$ D, Amjad Khan ${ }^{1 *}$, Komal Nawaz ${ }^{1}$,
} Siew Hua Gan ${ }^{3}$ and Gul Majid Khan ${ }^{1 *}$

\begin{abstract}
Background: Pakistan is facing a growing population of people living with human immunodeficiency (HIV). In this randomized controlled trial, we investigate if a pharmacist-led intervention can increase adherence to antiretroviral therapy (ART) for people living with HIV (PLWH).

Methods: Adults with HIV, who have been taking ART for more than 3 months were randomly assigned to receive either a pharmacist-led intervention or their usual care. Measures of adherence were collected at 1) baseline 2) just prior to delivery of intervention and 3) 8 weeks later. The primary outcomes were CD4 cell count and self-reported adherence measured with the AIDS Clinical Trial Group (ACTG) questionnaire.

Results: Post-intervention, the intervention group showed a statistically significant increase in CD4 cell counts as compared to the usual care group $(p=0.0054)$. In addition, adherence improved in the intervention group, with participants being 5.96 times more likely to report having not missed their medication for longer periods of time $(p=0.0086)$ while participants in the intervention group were 7.74 times more likely to report missing their ART less frequently $(p<0.0001)$.
\end{abstract}

Conclusions: The findings support the improvement in ART adherence and HIV management.

Trial registration: The trial is registered with Australian New Zealand Clinical Trials Registry (ACTRN12618001882213). Registered 20 November 2018.

Keywords: ART adherence, HIV, Counselling, Pharmacist intervention, Prevention

\section{Background}

The human immunodeficiency virus (HIV) is a global pandemic affecting mostly both low- and middle-income countries [1]. Pakistan, a lower to middle-income country, has seen a rapid growth in HIV epidemic [2]. Some factors contributing to this phenomena include low level of education on HIV transmission, poor infection control practices and insufficient HIV prevention programs,

\footnotetext{
* Correspondence: fudin@qau.edu.pk; amjadkhan@qau.edu.pk; gmkhan@qau.edu.pk

'Department of Pharmacy, Quaid-i-Azam University, Islamabad, Pakistan Full list of author information is available at the end of the article
}

particularly in relation to condom use among sexworkers, male homosexuals, transgenders and intravenous drug-users as well as poor safety on injection practices [2-4]. It is estimated that Pakistan has an estimated 160,000 people living with HIV (PLWH) [5] and the number is growing rapidly, making treatment programs a priority. Recently, some studies from Pakistan reported a low adherence to ART among intravenous and nonintravenous drug users [6]. Similarly, a systematic review was reported earlier to determine the relationship between socioeconomic status and adherence among the HIV patients in low- and middle-income countries

(c) The Author(s). 2020 Open Access This article is licensed under a Creative Commons Attribution 4.0 International License, which permits use, sharing, adaptation, distribution and reproduction in any medium or format, as long as you give appropriate credit to the original author(s) and the source, provide a link to the Creative Commons licence, and indicate if changes were made. The images or other third party material in this article are included in the article's Creative Commons licence, unless indicated otherwise in a credit line to the material. If material is not included in the article's Creative Commons licence and your intended use is not permitted by statutory regulation or exceeds the permitted use, you will need to obtain permission directly from the copyright holder. To view a copy of this licence, visit http://creativecommons.org/licenses/by/4.0/. The Creative Commons Public Domain Dedication waiver (http://creativecommons.org/publicdomain/zero/1.0/) applies to the data made available in this article, unless otherwise stated in a credit line to the data. 
demonstrating that a convincing evidence was not established between the two comparative groups [7]. However, another study reported the fact that various factors can influence adherence to ART. These include the disease status, therapy, and affiliation of the patient with the healthcare provider [8].

Fortunately, with the introduction of ART, the status of HIV/AIDS has changed from a lethal to chronic disease [9]. It is hypothesized that in order to achieve HIV viral suppression, adherence rates of at least $82-95 \%$ are ideal $[10,11]$ and should therefore be targeted. However, individuals in low- and middle-income countries are said to be 1.6 times more likely to have suboptimal adherence to ART [12]. In Pakistan specifically, data has indicated that $17 \%$ of people taking ART have suboptimal adherence [13] and the majority (81\%) of intravenous drug-users miss more than three ART treatments per month [6]. The suboptimal adherence is detrimental since it 1) can increase the risk of progression from HIV to AIDS [14], 2) increase the risk of drug resistance [15] and 3) threaten further spread of the disease [16]. Thus, interventions which can increase adherence to ART are urgently required. Moreover, the WHO drug resistance report 2012 stated that with the increased number of people accessing ART, the prevalence of pre-treatment drug resistance has increased in several low-income and middle-income countries [17]. Available data shows that pre-treatment drug resistance is significantly more prevalent in people with previous ART exposure and leads to virological failure [18].

Counselling is a key strategy that can improve ART adherence by enhancing awareness, emotional support and improving self-efficacy [19]. Pharmacists and other health professionals have similar consultation approaches which tend to vary during follow up. Many studies have suggested that by incorporating pharmacist in the multidisciplinary care, adherence to ART can be improved and virological suppression achieved [20]. Additionally, pharmacist-led interventions also incur some cost savings in terms of ART adherence treatment [21]. In fact, there is no disadvantages of pharmacist-led intervention documented to date. Individualized counselling with a strong educational component can address the cognitive, emotional, social and behavioral factors that impede adherence to ART [22]. Therefore, it is recommended that education is delivered at the beginning of treatment, at a single point during treatment, or on an ongoing basis [23].

Pharmacists who are routinely involved in providing education about medications, have seen a growth in their roles in relation to ART. The roles include medication monitoring, management of drug-related adverse events and adherence counselling [24-29] Indeed, pharmacists 1) are uniquely-placed to provide patients with individualized education and 2) have vital roles in improving ART adherence $[28,30]$. People living with HIV who receives pharmaceutical education believe that it is beneficial, particularly for managing drug interactions, side effects and missed doses [31]. The notion is supported by existing systematic review of randomized and non-randomized controlled trials, pre-post comparisons and cohort studies, which indeed confirmed a positive association between pharmacist-led interventions and ART adherence [32]. It is plausible that the pharmacistled intervention can break bad medication-taking behaviors and underline the importance and benefits of treatments on the patients.

The aforementioned pharmacist-led adherence systematic review research [32] was conducted in high-income countries which may not be applicable to the local setting in Pakistan. In fact, pharmacy-based research in Pakistan remains in its infancy and faces a number of challenges, including developing a clearly-defined role for pharmacists and earning acceptance from other clinicians [33]. Thus, there is a need to expand the role of pharmacy practice in Pakistan, particularly in the area of ART. In this study, we evaluated the effect of a pharmacist-led education and counselling intervention, compared with usual care, on ART adherence and HIV control among individuals with HIV living in Pakistan.

\section{Methods}

\section{Study design and participants}

This is a single-blinded randomized controlled trial (RCT) undertaken between September 2018 and February 2019 at the HIV Care Center, Pakistan Institute of Medical Sciences (PIMS), Islamabad, Pakistan. The inclusion criteria were: HIV positive sero-status, $>18$ years of age, taking ART for $>3$ months and not enrolled in another treatment adherence program. The exclusion criteria were: having incomplete baseline blood test, pregnancy, or a cognitive impairment that may prevent engagement with the intervention.

\section{Randomization and masking}

Following informed consents and collection of baseline measurements, participants were randomly assigned to either the 'pharmacist-led intervention' or 'usual care' group, based on a computer-generated block randomization schedule [34]. The randomization codes were concealed in unmarked, sealed envelopes and were allocated by a nurse who was not involved in either the outcome measurement or the intervention delivery. Participants remained blinded to the group and were unaware of the timeframes during which the intervention and usual care groups would receive the pharmacist-led intervention. Overall, the intervention group received the intervention at the start of the study period, whilst 
the usual care group received the intervention following the conclusion of the study. Cluster of differentiation 4 (CD4) count was collected by assessors who were blinded to the grouping, but measures of adherence were collected by an assessor who is not blinded to the study. Data analysis was completed by a researcher who was blinded to the allocation of the group.

\section{Procedures}

Prior to study enrolment, the participants received a single education and counselling session when their ART was started, led by a physician and administered according to the national guidelines [35]. Then whenever required, especially if ART was changed, a follow-up counselling was provided, this time by a nurse. During the eight-week study period, both groups continued to have access to this nurse-led education if required and collected their medicines from a pharmacy technician.

In addition to the usual care, the intervention group also received the pharmacist-led intervention involving a single face-to-face counselling (30-min session) and education. The intervention was delivered after the collection of baseline measures. The intervention was tailored to each participants' social and cultural background, their beliefs about the effectiveness of ART and their baseline level of adherence. Intervention fidelity was monitored by a lead clinician at the HIV center, who supervised random intervention sessions on a daily basis. The education was focused on HIV transmission, disease state, cure, treatment resistance, viral load and safe sex. The counselling component focused on personal barriers to taking medication and is aimed at helping participants understand their medication-taking behaviors while acknowledging the actions needed to maintain a high level of adherence. The counselling session included advice on the potential negative impact of diet and supplementary herbs or medicines on the effectiveness of ART.

\section{Outcomes}

The outcome measures were collected at baseline and at the end of the eight-week intervention period. The first primary outcome was CD4 cell count, which provides a measure of HIV disease progression as well as patients' immune status [36]. The information was collected from the medical records, both on the day of enrolment and at the end of the eight-week study period. Follow up measures were integrated with the participants' routine visits to the clinics in order to achieve the eight-week period between baseline and follow up.

The second primary outcome was a self-reported adherence to ART, as assessed using section D of the Adult AIDS Clinical Trials Group (AACTG) adherence instrument [37] which has been validated in a resourcelimited settings [38]. This section of the AACTG asks the participants on the details of the last time they missed they medication (if any) to be rated within the past week, 1-2 weeks, 2-4 weeks, 1-3 months, > 3 months, or never. Two secondary outcomes were recorded 1) the reasons for having missed the medications (section C, AACTG) and 2) adherence self-efficacy as well as medication beliefs (section A, AACTG). Section $\mathrm{C}$ determines how often in the past month, they have non-adherence being rated from 'often' to 'never' on a four-point Likert scale as well as the possible reasons for non-adherence. Section A asks three questions related to 1) the ability to take medications as directed, 2) beliefs about medication efficacy and 3) beliefs about whether skipped medications may result in ART resistance; rated from 'not at all sure' to 'extremely sure' on a four-point Likert scale. Participants also completed section B of the AACTG at baseline, to gauge the social support received.

\section{Sample size}

The sample size was calculated in order to detect a statistically significant difference in the mean self-reported adherence (Cohen'd $=0.5$ ) across two time-points within the intervention group using a repeated measures t-test at $80 \%$ power and a $5 \%$ type-I error-rate. The required sample size was 34 for each group (total 68); however this was elevated to 100 to account for the high dropout-rate in HIV adherence studies [39].

\section{Statistical analysis}

Data were analyzed using R (The R Foundation for Statistical Computing, Vienna,Austria) version 3.5.1 [40]. MASS version 7.3-51.1 [41], stats version 3.5.1 [40] and ggplot2 version 3.2.0 [42] were used to build statistical models, perform hypothesis tests and plot data. A detailed statistical analysis report with data visualizations and code snippets for the models is available as a supplementary file. The statistical analysis evaluated the treatment effect (the difference in the outcomes between the intervention and the usual care groups) on the two primary outcomes. The analysis was based on complete cases. However, multiple imputations were not performed as the outcome measure categories were the only cells which had missing data [43]. The data were fitted with linear regression models. A longitudinal approach was adopted by adjusting for the baseline characteristics to cater for the missing data [44]. CD4 cell count data was analyzed using a linear regression model which estimated the difference across the two groups. Selfreported adherence, the reasons for having missed medication, adherence self-efficacy and medication beliefs, were analyzed using three separate models. Each model estimated the effect of the intervention using ordinal logistic regression on the relevant Likert scale. 
Treatment effects were estimated as odd ratios, which provide the ratio of the odds of the participants giving a higher response on the relevant Likert scale in the intervention group compared to the usual care group. An odds ratio of 1 suggests that the participants in both groups are equally likely to give a higher response on the scale. All statistical models were adjusted for the baseline outcomes and for covariates including social support (section B of AACTG baseline instrument), age, gender, education, employment, marital status and the cause for HIV. The estimated treatment effects are reported together with their $95 \%$ confidence intervals $(p<$ 0.05).

\section{Results}

Figure 1 shows the consolidated standards of reporting trials (CONSORT) diagram from the screening step to study completion. Out of the 128 people screened for participation, 100 were eligible and were randomly assigned to either the intervention group $(n=50)$ or the usual care group $(n=50)$. All participants in the intervention group received the pharmacist-led intervention, but 17 dropped out or were lost to follow up. In the usual care group, three participants refused to take part immediately after randomization and another 14 dropped out during the intervention period or were lost to follow up. Finally, there were a total of 33 participants in each group.

\section{Socio-demographic characteristics and social support}

The baseline socio-demographic characteristics and selfreported level of support (section B, AACTG) are presented in Tables 1 and 2 respectively. Participants were predominantly male, uneducated and unemployed. The main modes of HIV transmission were sexual transmission and shared needles during drug use. Participants reported moderate levels of social support.

\section{HIV viral load: CD4 cell count}

The CD4 cell counts are presented in Fig. 2. The statistical model indicated a statistically significant increase in CD4 cell counts in the intervention group, postintervention (mean difference $=199.67$ [95\% CI 61.81337.53], $\mathrm{t}[48]=2.91, p=0.0054)$.

\section{Self-reported adherence: the last time medication was missed (section D, AACTG)}

The last time participants missed taking any of their medication(s) is presented in Fig. 3. At postintervention, there was a $36 \%$ increase in the number of participants in the intervention group who 'never' missed their medication, compared to only $3 \%$ in the usual care group. Additionally, compared to the usual care group, participants in the intervention group were 5.96 times more likely to report a higher response on the time scale which comprised the past week, 1-2 weeks, 2-4 weeks, 1-3 months, 3+ months, or never

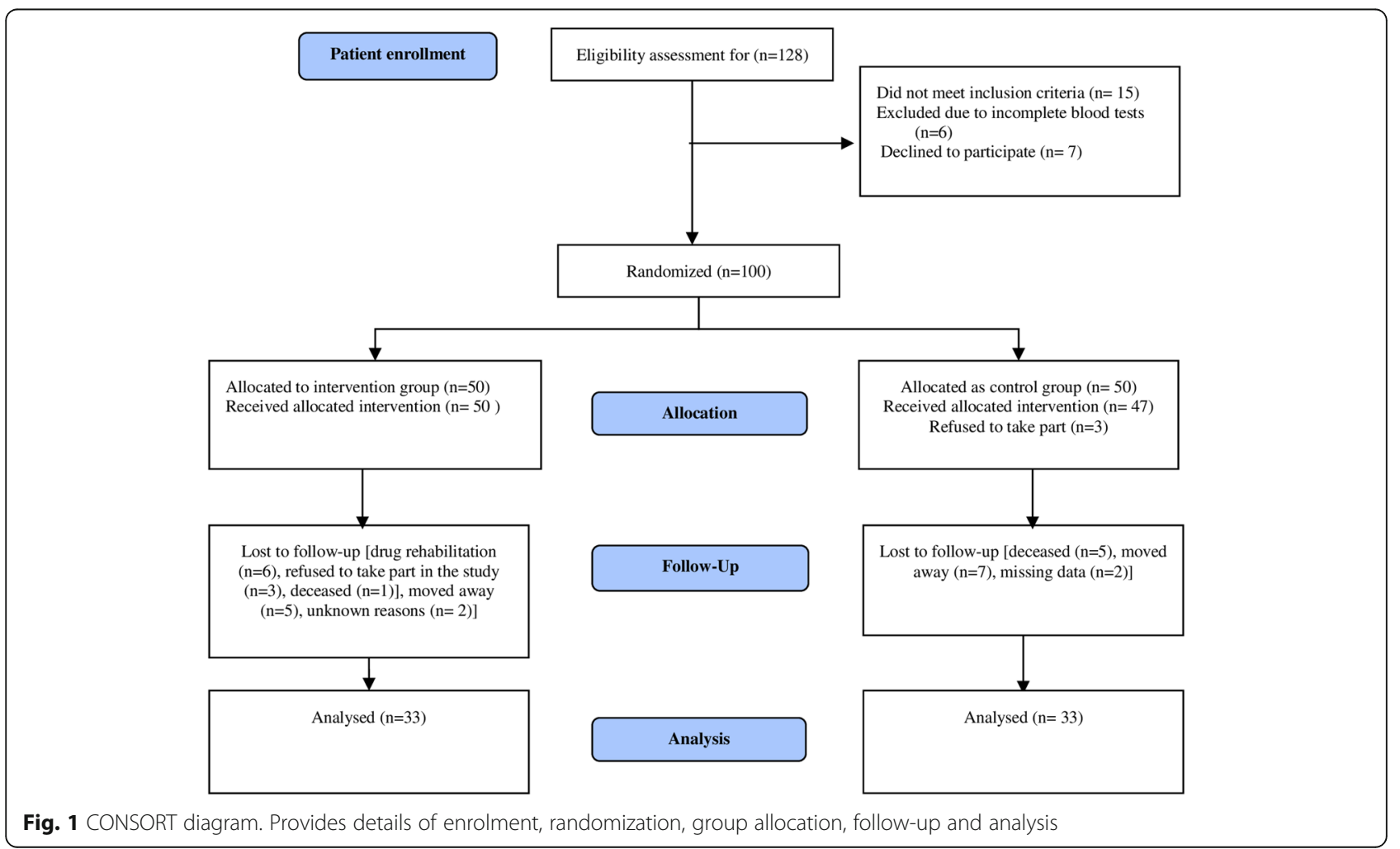


Table 1 Baseline sociodemographic characteristics

\begin{tabular}{lll}
\hline Sociodemographic characteristics & Usual care & Intervention \\
\hline Age mean (SD) & $31.39(9.53)$ & $36.18(12.24)$ \\
Gender, n (\%) & & \\
Male & $18(54.55)$ & $23(69.70)$ \\
Female & $10(30.30)$ & $10(30.30)$ \\
Transgender & $5(15.15)$ & $\mathrm{NA}$ \\
Education, $\mathrm{n}(\%)$ & & \\
Educated & $6(18.18)$ & $6(18.18)$ \\
Uneducated & $27(81.82)$ & $27(81.82)$ \\
Employment, $\mathrm{n}(\%)$ & & $10(30.30)$ \\
Employed & $15(45.45)$ & $23(69.70)$ \\
Unemployed & $18(54.55)$ & \\
Marital status, n (\%) & & $21(63.64)$ \\
Married & $18(54.55)$ & $11(33.33)$ \\
Unmarried & $14(42.42)$ & $1(3.03)$ \\
Divorced & $1(3.0)$ & $25(75.76)$ \\
HIV transmission cause, $\mathrm{n}(\%)$ & & $5(15.15)$ \\
Sex & $23(69.70)$ & $5(15.15)$ \\
Shared needles & $5(15.15)$ & \\
Other & & \\
\hline
\end{tabular}

missed medication (OR [95\% CI] $=5.96$ [1.57-22.55], $\mathrm{z}=2.63, p=0.0086)$. Moreover, there was a statisticallysignificant association between higher responses (longer periods of adherence) and social support (B2) $\left(\chi^{2}[3]=\right.$ $8.44, p=0.0377)$, such that people with lower levels of social support were more likely to be adherent postintervention (somewhat satisfied/very dissatisfied OR $[95 \% \mathrm{CI}]=0.06$ [0.003-1.06]). There was also an association between the cause of HIV transmission and higher responses $\left(\chi^{2}[2]=9.15, p=0.0103\right)$, such that participants who reported sexual transmission as the cause of

Table 2 Self-reported level of support

\begin{tabular}{|c|c|c|}
\hline Social support & $\begin{array}{l}\text { Usual care } \\
\mathrm{N}(\%)\end{array}$ & $\begin{array}{l}\text { Intervention } \\
\mathrm{N}(\%)\end{array}$ \\
\hline \multicolumn{3}{|c|}{$\begin{array}{l}\text { B1: In general, how satisfied are you with the overall support you ge } \\
\text { from your friends and family members? }\end{array}$} \\
\hline Very dissatisfied & $7(21.21)$ & $5(15.15)$ \\
\hline Somewhat dissatisfied & $10(30.30)$ & $8(24.24)$ \\
\hline Somewhat satisfied & $13(39.39)$ & $14(42.42)$ \\
\hline Very satisfied & $3(9.09)$ & $6(18.18)$ \\
\hline \multicolumn{3}{|c|}{$\begin{array}{l}\text { B2: To what extent do your friends or family members help you } \\
\text { remember to take your medication? }\end{array}$} \\
\hline Very dissatisfied & $9(27.27)$ & $4(12.12)$ \\
\hline Somewhat dissatisfied & $8(24.24)$ & $9(27.27)$ \\
\hline Somewhat satisfied & $7(21.21)$ & $10(30.3)$ \\
\hline Very satisfied & $9(27.27)$ & $10(30.3)$ \\
\hline
\end{tabular}

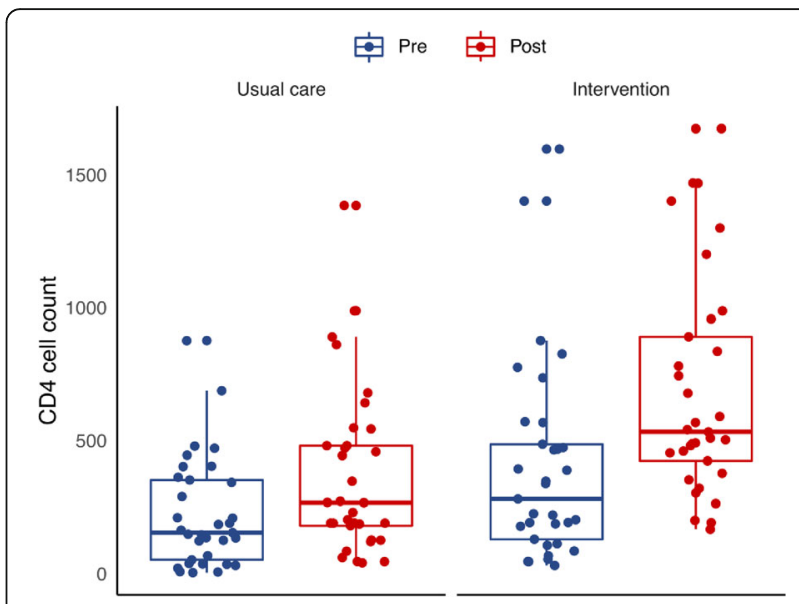

Fig. 2 CD4 cell count results. Pre- and post-intervention plots illustrating CD4 cell counts of individual participants (dots) and usual care and intervention groups (boxes with medians and interquartile ranges)

getting the disease were less likely to adhere to medication compared to those who reported other causes of transmission (other/sex OR $[95 \%$ CI $]=23.14$ [2.29234.12]). For further details regarding effect sizes please refer to the supplementary file.

\section{Reasons for having missed medication in the past month} (section C, AACTG)

The participants have rated 14 possible reasons for them having missed ART on the 'often-sometimes-rarelynever' scale where a higher response indicates that the reason is less likely to have contributed to missing the medications in the past month. Post-intervention, participants in the intervention group were 7.74 times more likely to report a higher response on the 'often-

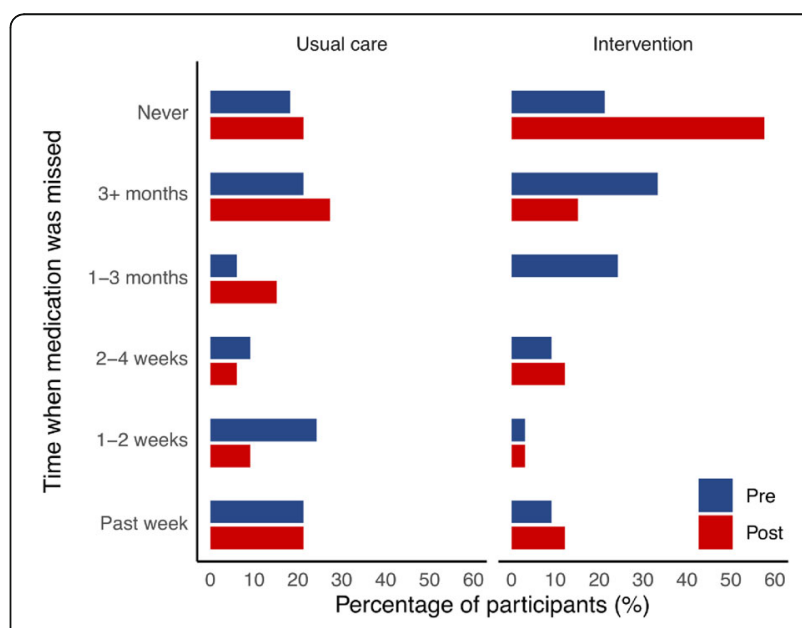

Fig. 3 Self-reported adherence results. Pre- and post-intervention plots illustrating self-reported timeframes in which medication was last missed for the usual care and intervention groups 
sometimes-rarely-never' scale (OR $[95 \% \mathrm{CI}]=7.74$ [4.68$12.81], \mathrm{z}=7.96, p<0.0001)$. Moreover, there was a statistically-significant association between higher responses and marital status $\left(\chi^{2}[2]=10.71, p=0.0047\right)$, gender $\left(\chi^{2}[2]=16.83, p=0.0002\right)$ as well as cause of infection $\left(\chi^{2}[2]=27.32, \mathrm{p}<0.0001\right)$ where unmarried participants were more likely to report higher responses (unmarried/married OR [95\% CI] $=2.88$ [1.50-5.49]). Additionally, transgender participants were less likely to report higher responses (transgender/male OR $[95 \% \mathrm{CI}]=0.23[0.11-0.48])$. Moreover, participants who reported sexual transmission as the cause of infection were less likely to report higher responses compared to those who reported all other reasons for HIV transmission (other/sex OR $[95 \%$ CI $]=7.87$ [3.19-19.42]). The supplementary file records further details regarding effect sizes. The most common reasons participants had 'often', 'sometimes', or 'rarely' missed their medications, were "being away from home", "being busy", "forgetful" and "having too many pills to take". The reasons which had the response 'never' are presented in Fig. 4; these indicate the reasons which are not, or no longer, contributing to missed medications.

\section{Adherence self-efficacy and medication beliefs (section a, AACTG)}

The responses to the three questions related to adherence self-efficacy and medication beliefs indicated that there were minimal changes in the usual care group (upper graphs) (Fig. 5). However, for the intervention group (lower graphs), adherence, self-efficacy and medication beliefs changed substantially where at postintervention, a majority (>75\%) of the participants were 'extremely sure' that 1) they could take medication as directed 2) the medication would have a positive effect and 3) not taking their medicine would lead to ART resistance. The ordinal logistic regression model for this outcome measure failed to converge to a feasible solution as most of the participants in the post-intervention cell gave the same response as ('never') while leaving other cells empty.

\section{Discussion}

To our knowledge, this RCT is the first to report on the effect of a pharmacist-led ART adherence intervention in Pakistan. The findings may be applicable to lowermiddle income countries. Eight weeks following the delivery of a single 30-min session of pharmacist-led

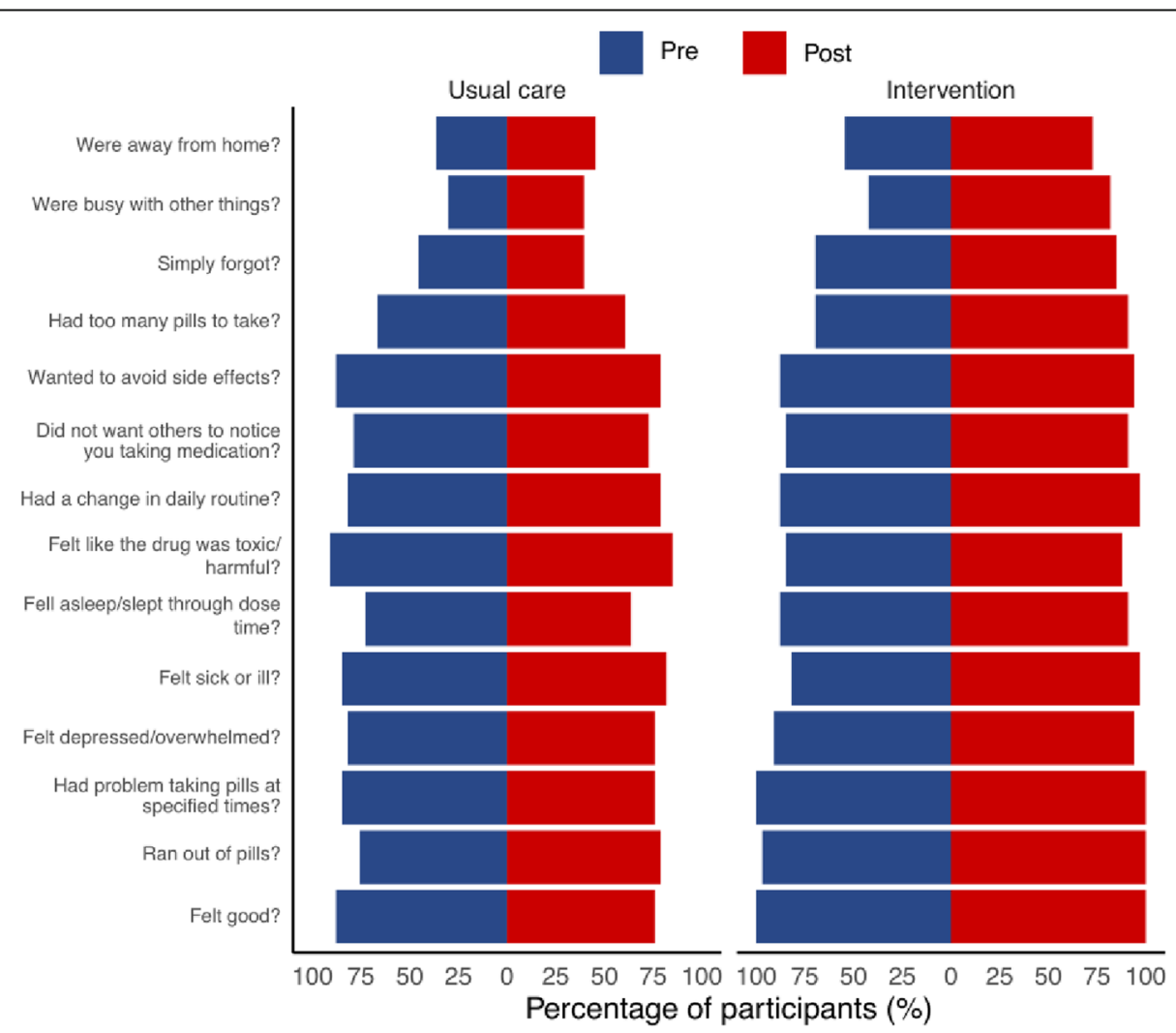

Fig. 4 Factors related to adherence. Pre- and post-intervention plots illustrating the percentage of participants that reported reasons as 'never' causing them to miss their medications in the past month. An increased percentage post-intervention equates to fewer people missing their medication for this reason 


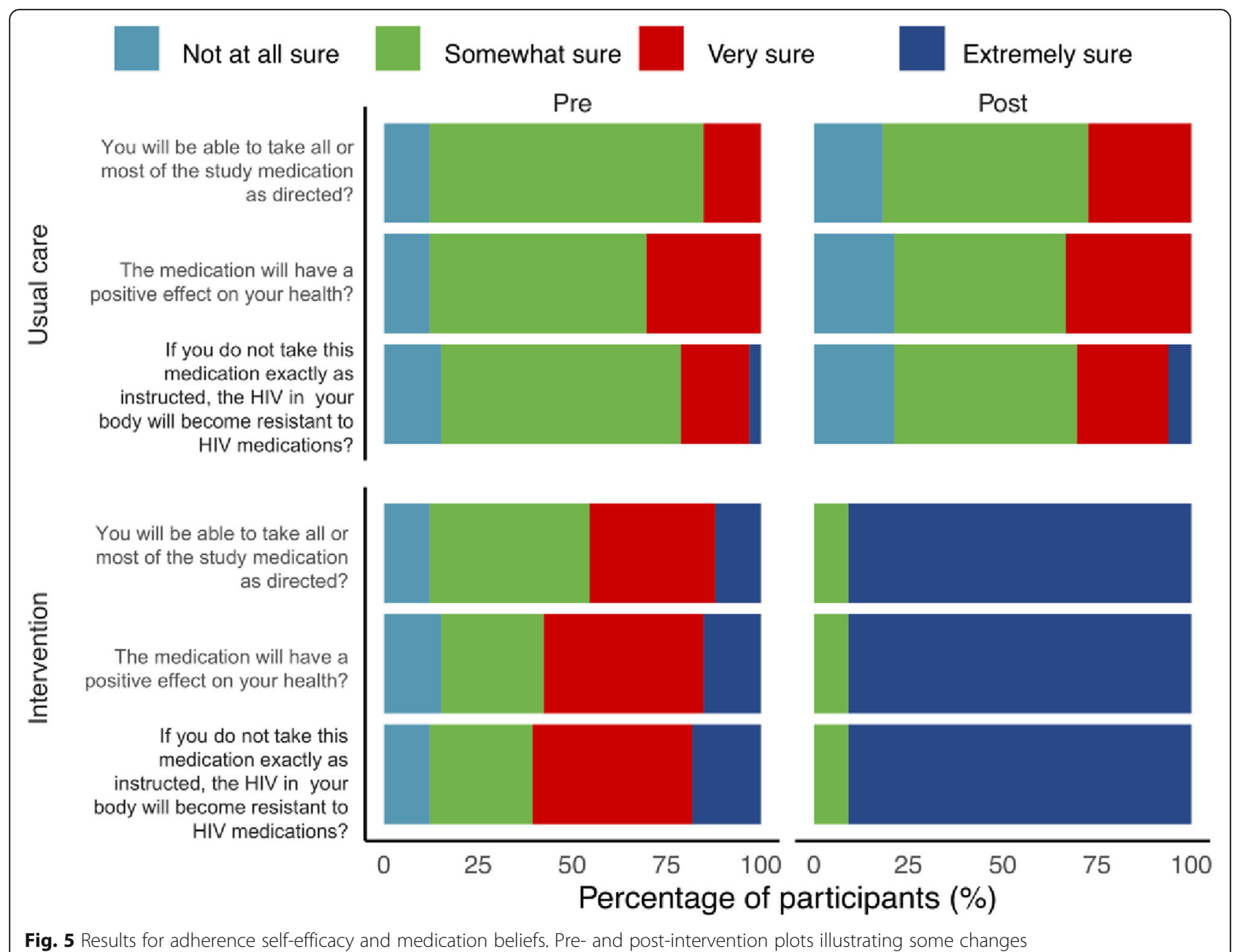

education and counselling, participants in the intervention group were statistically significantly more likely to report improved adherence. In addition, the intervention group had a statistically significant higher CD4 counts, indicating improved HIV disease status and immune system function [36]. Increased CD4 cell counts have been reported following other pharmacist-led adherence interventions [27, 45] Given the association between good ART adherence and optimal CD4 cell response [46], it is plausible that improved adherence levels contribute to improved CD4 counts and that the pharmacist-led intervention can ameliorate status of HIV. Although other clinical measures were not recorded, literatures would suggest that improved CD4 cell counts would make the individuals less susceptible to opportunistic infections [36] and have a lower risk of progression to AIDS and death [47].

The adherence findings were supported by nonsystematic [23] and systematic $[19,48]$ literature reviews, which have shown the beneficial effects of education and counselling interventions on adherence to ART. Previous adherence interventions have been delivered by counsellors, nurses and community support workers and less commonly, by pharmacists [48]. Whilst the majority of research into pharmacist-led ART interventions has been observational or uncontrolled (pre-post) [32], two RCTs have previously been reported [29, 49], to which our results are comparable to. Ratbun et al. [29] conducted an RCT to explore the effect of a 12-week pharmacist-led intervention compared to the usual care. The intervention comprised of an initial 1.0 to 1.5 -h session of education and counselling, a two-week follow-up visit and additional visits as well as telephone follow-up when required. The findings showed improved adherence and viral load post-intervention. In another study, Levy et al. [49] conducted a quasi-RCT and demonstrated improved self-reported adherence following a pharmacist-led intervention which comprised of a 2-h session of education and counselling, medication adherence aids and telephone advice as required.

Two further non-randomized controlled trials have investigated the effect of pharmacist-led counselling over 
five monthly-sessions and have shown 1) increased adherence [50] 2) a slower decline in adherence [51] and 3 ) decreased rates of hospitalization and opportunistic infections [50] in the intervention group when compared with the usual care. In comparison to our study, these pharmacist-led interventions were of longer duration and were provided at multiple time-points; thus, it is promising to see that the single 30-min intervention in our study significantly improved adherence and disease state indicating that $30-\mathrm{min}$ is a minimum duration. An intervention which of short-duration is likely to be more cost-effective and therefore has better potential to be successfully implemented especially in lower- to middleincome countries like Pakistan. Having said this, a costbenefit analysis was not conducted in our study and should be considered in future research.

The most common reasons for non-adherence were "being away from home", "being busy" and "forgetful", which is in line with literatures on ART $[37,52]$. In the present study, the pharmacist tends to provide advice on the medications when travelling and when busy which are more likely to contribute to the fact that these factors have a low influence on non-adherence postintervention (Fig. 3). The pharmacist-led intervention also improved 1) the participants' beliefs in their ability to correctly take medications and 2) participants' understanding on the benefits of ART and the risks of ART resistance. These changes may have improved motivation [53] and contributed to improvements in the overall adherence. Therefore, pharmacists and clinicians should ensure that these factors are addressed in any ART adherence program.

Socio-demographic factors are known to influence adherence. Economic costs of treatment were not a factor in this study, but travel costs may have limited the timely collection of ART medication. Transgender participants were more likely to report non-adherence, which is consistent with previous literature [54]. Detectable viral loads and failure to achieve viral suppression were associated with lower adherence among transgenders. Moreover, HIV related, and gender related stigma also plays important role in the adherence [54]. Those who reported sexual transmission as the cause to be less likely to be adherent to medication. Previous studies reported poor adherence is associated with unprotected sex. People who believe that they are less infectious when their blood viral load is undetectable, a result of treatment adherence, reduce condom use and increase unprotected sex. Contrary to other studies, although social support was associated with adherence, participants who had lower social support had higher adherence to medications post-intervention. Whilst this finding contrasts with literature in which higher social support has been associated with improved adherence [55], there are cases where non-disclosure of HIV status to family or friends led to some individuals having missed their medications due to fear or stigma of rejection $[56,57]$. It is not known whether fear of stigma also contributed to the associations found in this study between marriages with lower adherence. Further qualitative research is needed to understand the underlying reasons for nonadherence specific to Pakistan to allow pharmacists to tailor their interventions more specifically to these needs.

Our study has some limitations, in which the study was performed under a limited budget in a resourcelimited setting. CD4 counts were collected pragmatically from medical records and were therefore not available on some occasions. The lead investigator who delivered the intervention also administered the AACTG instrument and therefore was not blinded to group allocation. This may have produced some bias in measuring selfreported adherence and in the secondary measures. Fortunately, the possibility of bias is somewhat negated by the fact that the blinded CD4 cell count measures strongly support the data for adherence. Nevertheless, any future work, should ensure the AACTG instrument is administered by a blinded assessor.

It was noted that baseline levels of adherence differed between the usual care and intervention groups ( $45 \%$ vs $12 \%$ had missed medications in the previous $1-2$ weeks, see Fig. 3), which was unexpected, given that participants were randomly allocated to groups. However, these baseline differences did not lead to biasness in the findings, as the statistical model corrected for baseline measures [58]. It has been suggested that permanent behavior change is likely to need long-term input [23] and therefore the eight-week follow up in this study was likely insufficient to determine lasting changes. Given ART medication needs to be taken long term, future researchers should monitor adherence over a longer period and consider options for providing low-cost follow up at regular intervals.

\section{Conclusions}

The study demonstrated that a brief pharmacist-led education and counselling intervention can significantly improve ART adherence and HIV disease state in people with HIV living in Pakistan. In addition, pharmacist-led intervention also ameliorated participants' beliefs in their ability to correctly take medications and improve their understanding on the benefits of ART as well as the risks of the development of ART resistance. This supports the integral role of pharmacists in patient care and the positive impact they can have on patient outcomes. Further research is needed to test the efficacy of intervention in other HIV centers and to explore ways to optimize its delivery. 


\section{Supplementary Information}

The online version contains supplementary material available at https://doi. org/10.1186/s12879-020-05571-w.

\section{Additional file 1.}

\section{Abbreviations}

AACTG: Adult AIDS Clinical Trials Group; ACTG: AIDS Clinical Trial Group; ART: Antiretroviral therapy; CD4: Cluster of differentiation 4; CONSORT: Consolidated standards of reporting trials; HIV: Human immunodeficiency; PIMS: Pakistan Institute of Medical Sciences; RCT: Randomized controlled trial

\section{Acknowledgements}

This study was supported by the Quaid-I-Azam University, Islamabad, Pakistan, as part of a Master of Pharmacy Practice thesis.

\section{Authors' contributions}

ZFC and KN conceived the idea for the study. ZFC, UR, FD, AK, KN and GMK developed the study design. ZFC managed ethical approval, trial registration, data collection, intervention delivery and data processing. FD and GMK supervised the study. UR performed the statistical analysis and created the data visualizations. ZFC, UR and SO interpreted the results. ZFC wrote the first draft of the manuscript. AK and GSH critically revised the manuscript and SO revised and wrote the second draft of the manuscript. All authors edited, reviewed and approved the final manuscript.

\section{Funding}

None.

\section{Availability of data and materials}

All data generated or analyzed during this study are included in this current article. The datasets used and/or analyzed during the current study are available from the corresponding author on reasonable request.

\section{Ethics approval and consent to participate}

The study was approved by the Quaid-i-Azam University Bioethics Committee (BEC-FBS-QAU2018-107) and Ethics Review Board of Shaheed Zulfiqar Ali Bhutto Medical University, PIMS (F.1-1/2015/ERB/SZABMU/358) which comply with the Declaration of Helsinki. The trial was registered with the Australian New Zealand Clinical Trials Registry (ACTRN12618001882213). All eligible participants $(n=100)$ provided written informed consents.

\section{Consent for publication}

Not applicable.

\section{Competing interests}

We declare no competing interests.

\section{Author details}

'Department of Pharmacy, Quaid-i-Azam University, Islamabad, Pakistan. ${ }^{2}$ Health and Rehabilitation Research Institute, Auckland University of Technology (AUT), Auckland, New Zealand. ${ }^{3}$ School of Pharmacy, Monash University Malaysia, 47500 Bandar Sunway, Selangor Darul Ehsan, Malaysia.

Received: 15 July 2020 Accepted: 31 October 2020

Published online: 23 November 2020

\section{References}

1. Wang H, Wolock TM, Carter A, et al. Estimates of global, regional and national incidence, prevalence and mortality of HIV, 1980-2015: the global burden of disease study 2015. Lancet HIV. 2016;3(8):e361-e87.

2. UNAIDS. UNAIDS 2018 implementation of the HIV prevention 2020 road map.

3. Altaf A. Delays and gaps in HIV programs in Pakistan. The Lancet HIV. 2018; 5(12):e678-e9.

4. UNAIDS. AIDS info. Country factsheet Pakistan. UNAIDS; 2018

5. Joint United Nations Program on HIV/AIDS (UNAIDS). AIDS info 2019 [Available from: https://aidsinfo.unaids.org/.
6. Ali B, Nisar N, Nawab F. Adherence to antiretroviral therapy in HIV-positive, male intravenous drug users in Pakistan. East Mediterr Heal J. 2018;24(3): 237-42.

7. Peltzer K, Pengpid S. Socioeconomic factors in adherence to HIV therapy in low- and middle-income countries. J Health Popul Nutr. 2013;31(2):150-70.

8. Ammassari $\mathrm{A}$, et al. Correlates and predictors of adherence to highly active antiretroviral therapy: overview of published literature. J Acquir Immune Defic Syndr. 2002;31(3):S123-7.

9. Deeks SG, Lewin SR, Havlir DV. The end of AIDS: HIV infection as a chronic disease. Lancet. 2013;382(9903):1525-33.

10. Byrd KK, Hou JG, Hazen R, et al. Antiretroviral adherence level necessary for HIV viral suppression using real-world data. J Acquir Immune Defic Syndr. 2019;82(3):245-51. https://doi.org/10.1097/QAl.0000000000002142.

11. Squier $C$, Wagener MMM, Singh $N$, et al. Adherence to protease inhibitor therapy and outcomes in patients with HIV infection. Ann Intern Med. 2000; 133(1):2130

12. Bijker $\mathrm{R}$, et al. Journal of the International AIDS Society. 2017;20:21218. https://doi.org/10.7448/IAS.20.1.21218.

13. Tahir NB, Uddin QT. Treatment adherence and outcomes of antiretroviral agents in HIV positive patients. J College Phys Surg Pakistan. 2014;24(9):6458.

14. Kitahata MM, Reed SD, Dillingham PW, et al. Pharmacy-based assessment of adherence to HAART predicts virologic and immunologic treatment response and clinical progression to AIDS and death. Int J STD AIDS. 2004; 15(12):803-10.

15. Nachega JB, Marconi VC, van Zyl GU, et al. HIV treatment adherence, drug resistance, Virologic failure: evolving concepts. Infect Disord Drug Targets. 2011;11(2):167-74

16. Hosseinipour M, Cohen MS, Vernazza PL, Kashuba AD. Can antiretroviral therapy be used to prevent sexual transmission of human immunodeficiency virus type 1? Clin Infect Dis. 2002;34(10):1391-5.

17. WHO. WHO HIV Drug Resistance Report 2012. [Available from: http://apps. who.int/iris/bitstream.

18. BAVARO DF, Di Carlo D, Rossetti B, Bruzzone B, et al. Pretreatment HIV drug resistance and treatment failure in non-Italian HIV-1-infected patientsenrolled in ARCA. Antivir Ther. 2020. https://doi.org/10.3851/ IMP3349. PMID: 32118584.

19. Musayon-Oblitas Y, Carcamo C, Gimbel S. Counseling for improving adherence to antiretroviral treatment: a systematic review. AIDS Care. 2019; 31(1):4-13.

20. Rocha BS, Silveira MPT, Moraes CG, et al. Pharmaceutical interventions in antiretroviral therapy: systematic review and meta-analysis of randomized clinical trials. J Clin Pharm Ther. 2015:40(3):251-8.

21. Dilworth TJ, Klein PW, Mercier RC, et al. Clinical and economic effects of a pharmacist-administered antiretroviral therapy adherence clinic for patients living with HIV. J Manag Care Spec Pharm. 2018;24(2):165-72.

22. Pradier C, Bentz L, Spire B, et al. Efficacy of an educational and counseling intervention on adherence to highly active antiretroviral therapy: French prospective controlled study. HIV Clin Trials. 2003;4(2):121-31.

23. Beith A, Johnson A. Interventions to improve adherence to antiretroviral therapy: a review of the evidence. USAID, editor; 2006.

24. Penn C, Watermeyer J, Evans M. Why don't patients take their drugs? The role of communication, context and culture in patient adherence and the work of the pharmacist in HIV/AIDS. Patient Educ Couns. 2011; 83(3):310-8.

25. Foisy MM, Akai PS. Pharmaceutical care for HIV patients on directly observed therapy. Ann Pharmacother. 2004;38(4):550-6.

26. Geletko SM, Poulakos MN. Pharmaceutical services in an HIV clinic. Am J Health Syst Pharm. 2002;59(8):709-13.

27. March K, Mak M, Louie SG. Effects of pharmacists' interventions on patient outcomes in an HIV primary care clinic. Am J Health Syst Pharm. 2007; 64(24):2574-8.

28. Tseng A, Foisy M, Hughes CA, et al. Role of the pharmacist in caring for patients with HIV/AIDS: clinical practice guidelines. Can J Hosp Pharm. 2012; 65(2):125-45.

29. Rathbun RC, Farmer KC, Stephens JR, Lockhart SM. Impact of an adherence clinic on behavioral outcomes and virologic response in treatment of HIV infection: a prospective, randomized, controlled pilot study. Clin Ther. 2005; 27(2):199-209.

30. Cantwell-McNelis K, James CW. Role of clinical pharmacists in outpatient HIV clinics. Am J Health Syst Pharm. 2002;59(5):447-52. 
31. Guerrault MN, Leclerc C, Langevin S, Merian-Brosse L, Brossard D, Welker $Y$ Study of the usefulness of pharmacist consultations for patients on antiretroviral regimens. Presse Med. 2005;34(20 Pt 2):1563-70.

32. Saberi P, Dong BJ, Johnson MO, Greenblatt RM, Cocohoba JM. The impact of HIV clinical pharmacists on HIV treatment outcomes: a systematic review. Patient Preference Adherence. 2012;6:297.

33. Khan T. Challenges to pharmacy and pharmacy practice in Pakistan. Australas Med J. 2011;4(4):230.

34. Urbaniak GC, Plous S. Research Randomizer (Version 4.0) 2013 [cited 2018 September 1]. Available from: https://www.randomizer.org/.

35. National Institute of Health Islamabad. Counselling for HIV/AIDS. The National Guidelines. 2001 [cited 2019 May 16]. Available from: http://www. nacp.gov.pk/library/reports/Advocacy.

36. Ford N, Meintjes G, Vitoria M, Greene G, Chiller T. The evolving role of CD4 cell counts in HIV care. Curr Opin HIV AIDS. 2017;12(2):123-8.

37. Chesney MA, Ickovics JR, Chambers DB, et al. Self-reported adherence to antiretroviral medications among participants in HIV clinical trials: the AACTG adherence instruments. Aids Care Psychol Socio-Med Aspects Aids/ Hiv. 2000;12(3):255-66.

38. Munoz M, Finnegan K, Zeladita J, et al. Community-based DOT-HAART accompaniment in an urban resource-poor setting. AIDS Behav. 2010;14(3): 721-30.

39. Unge C, Sodergard B, Marrone G, et al. Long-term adherence to antiretroviral treatment and program drop-out in a high-risk urban setting in sub-Saharan Africa: a prospective cohort study. PLoS One. 2010;5(10): e13613.

40. Team RC. R: a language and environment for statistical computing; 2015; 2018.

41. Venables W, Ripley B. Modern applied statistics (Fourth S., editor). New York: Springer; 2002.

42. Wickham H. ggplot2: elegant graphics for data analysis: Springer; 2016.

43. Jakobsen JC, Gluud C, Wetterslev J, Winkel P. When and how should multiple imputation be used for handling missing data in randomised clinical trials-a practical guide with flowcharts. BMC Med Res Methodol. 2017;17(1):162.

44. Herbert RD, Kasza J, Bø K. Analysis of randomised trials with long-term follow-up. BMC Med Res Methodol. 2018;18(1):48.

45. Ma A, Chen DM, Chau FM, Saberi P. Improving adherence and clinical outcomes through an HIV pharmacist's interventions. Aids Care Psychol Socio Med Aspects Aids/Hiv. 2010;22(10):1189-94.

46. Abrogoua DP, Kablan BJ, Kamenan BA, Aulagner G, N'Guessan K, Zohore C. Assessment of the impact of adherence and other predictors during HAART on various CD4 cell responses in resource-limited settings. Patient Prefer Adherence. 2012;6:227-37.

47. Sheean, et al. 2013. NIH Public Access. Bone. 2008;23(1):1-7.

48. Chaiyachati KH, Ogbuoji O, Price M, Suthar AB, Negussie EK, Barnighausen T. Interventions to improve adherence to antiretroviral therapy: a rapid systematic review. AIDS. 2014;28(Suppl 2):S187-204.

49. Levy RW, Rayner CR, Fairley C, et al. Multidisciplinary HIV adherence intervention: a randomized study. AIDS Patient Care STDs. 2004;18(12):72835 .

50. McPherson-Baker S, Malow RM, Penedo F, Jones DL, Schneiderman N, Klimas NG. Enhancing adherence to combination antiretroviral therapy in non-adherent HIV-positive men. AIDS Care. 2000;12(4):399-404.

51. Krummenacher I, Cavassini M, Bugnon O, Spirig R, Schneider MP. The Swiss HIV cohort study. Antiretroviral adherence program in HIV patients: a feasibility study in the Swiss HIV cohort study. Pharm World Sci. 2010;32: 776-86.

52. Okoronkwo I, Okeke U, Chinweuba A, Iheanacho P. Nonadherence Factors and Sociodemographic Characteristics of HIV-Infected Adults Receiving Antiretroviral Therapy in Nnamdi Azikiwe University Teaching Hospital, Nnewi, Nigeria. ISRN AIDS. 2013;2013:843794

53. Fisher JD, Fisher WA, Amico KR, Harman JJ. An information-motivationbehavioral skills model of adherence to antiretroviral therapy. Health Psychol. 2006;25(4):462-73.

54. Baguso GN, Gay CL, Lee KA. Medication adherence among transgender women living with HIV. AIDS Care. 2016;28(8):976-81.

55. Li XM, Yuan XQ, Rasooly A, Bussell S, Wang JJ, Zhang WY. An evaluation of impact of social support and care-giving on medication adherence of people living with HIV/AIDS: a nonrandomized community intervention study. Medicine (Baltimore). 2018;97(28):e11488.
56. Rao D, Kekwaletswe TC, Hosek S, Martinez J, Rodriguez F. Stigma and social barriers to medication adherence with urban youth living with HIV. AIDS Care. 2007;19(1):28-33.

57. Kumarasamy N, Safren SA, Raminani SR, et al. Barriers and facilitators to antiretroviral medication adherence among patients with HIV in Chennai, India: a qualitative study. AIDS Patient Care STDs. 2005;19(8):526-37.

58. de Boer MR, Waterlander WE, Kuijper LD, Steenhuis IH, Twisk JW. Testing for baseline differences in randomized controlled trials: an unhealthy research behavior that is hard to eradicate. Int J Behav Nutr Phys Act. 2015;12(1):4.

\section{Publisher's Note}

Springer Nature remains neutral with regard to jurisdictional claims in published maps and institutional affiliations.

\section{Ready to submit your research? Choose BMC and benefit from:}

- fast, convenient online submission

- thorough peer review by experienced researchers in your field

- rapid publication on acceptance

- support for research data, including large and complex data types

- gold Open Access which fosters wider collaboration and increased citations

- maximum visibility for your research: over $100 \mathrm{M}$ website views per year

At BMC, research is always in progress.

Learn more biomedcentral.com/submissions 